\title{
HABITAT PREFERENCE AND ABUNDANCE OF MOLE CRAB BASED ON SEA TIDES IN COASTAL AREA OF KEBUMEN REGENCY
}

\author{
Tri Desi $^{1}$. Suryanti Suryanti ${ }^{1}$. Niniek Widyorini ${ }^{1}$
}

Ringkasan Mole crab is an important resource in the food chain cycle and an initial level consumers in sandy areas. Mole crab lives in the swash zone that is affected by sea tides. Comparison of habitat and abundance of each station based on tides in terms of the type of utilization of the study location. The purpose of this study was to determine the abundance at high tide and low tide, species, and habitat preferences of mole crab, also to determine the relationship between their habitat preferences and their abundance. The method used in this study was descriptive exploratory and uses purposive random sampling technique. Abundance data collection was done by using a $10 \times$ 10meter transect quadrant at two spring tides and two neap tides in the swash zone area. The results showed that the abundance of mole crab at high tide was 214 - 239 ind/100m2 and at low tide was 378 509 ind/100m2. There are three types

\footnotetext{
1) Program Studi Manajemen Sumberdaya Perairan, Departemen Sumberdaya Akuatik, Fakultas Perikanan dan Ilmu Kelautan, Universitas Diponegoro, Jl. Prof. Soedarto, SH, Tembalang, Semarang, Jawa Tengah 50275, Telp/Fax. +6224 7474698

E-mail: tridesi1205@gmail.com
}

of mole crab that has been found, Emerita emeritus, Hippa adactyla and Albunea symmysta. Favored habitat of mole crab in coast area of Kebumen Regency has a flat to sloping beach, wide swash zone at high tide 14.5 - $24.5 \mathrm{~m}$, and at low tide is $20-32.5 \mathrm{~m}$, medium sized beach sand (0.25-0.5mm), and has low organic material values. The results of the PCA (Principal Component Analysis) analysis that the sediment grain size and the width of the swash zone have a positive correlation with the abundance of mole crab.

Keywords molecrab, habitat, abudance, kebumen

\section{PENDAHULUAN}

Undur-undur laut atau yang biasanya dikenal dengan "yutuk" merupakan salah satu jenis hewan krustasea. Hewan ini hidup dengan menggali pasir di daerah sapuan ombak (swash zone) baik saat pasang maupun saat surut. Yutuk memanfaatkan gelombang untuk menggali lubang yang digunakan sebagai tempat mencari detritus sebagai makanannya. Selama hidupnya, hewan ini mem- 
punyai perilaku yang khas. Saat ombak datang, undur-undur laut akan keluar dan melompat dari pasir pantai, yang kemudian akan masuk kembali pada saat ombak kembali menuju laut. Menurut Dewi et al. (2019) bahwa kelimpahan undur-undur laut lebih banyak saat air laut surut dibandingkan saat air laut pasang. Hal ini dimungkinkan karena undur-undur laut mencari makanan berupa detritus saat air laut surut.

Hewan tersebut memiliki fungsi ekonomis yang dimanfaatkan oleh nelayan pesisir selatan pantai Jawa Tengah. Undur-undur laut dijual dalam bentuk olahan maupun mentahan. Bentuk olahan undur-undur laut salah satunya adalah "peyek yutuk" yang menjadi makanan khas oleh-oleh pantai selatan Jawa Tengah. Selain fungsi ekonomis undurundur laut juga memiliki fungsi ekologis yang cukup penting yaitu undurundur laut memiliki peran sebagai konsumen pada ingkat pertama dalam rantai makanan di ekosistem pantai berpasir (Wardiatno et al., 2014).

Penelitian ini bertujuan untuk mengetahui kelimpahan pada saat pasang dan surut, jenis, dan preferensi habitat undurundur laut serta untuk mengetahui hubungan antara preferensi habitat dengan kelimpahannya di pantai Kabupaten Kebumen.

\section{MATERI DAN METODE}

Penelitian dilakukan pada bulan OktoberNovember 2019 di Pantai Sawangan, TPI Pantai Bopong, dan Pantai Bopong, Kabupaten Kebumen, Jawa Tengah. Materi yang digunakan dalam penelitian ini adalah adalah undur-undur laut dan sedimen pantai yang ditemukan di Pantai Sawangan, Pantai Bopong dan TPI
Pantai Bopong Kabupaten Kebumen, Jawa Tengah. Variabel utama preferensi habitat yang diukur meliputi luas swash zone, kemiringan pantai, ukuran butir sedimen, warna sedimen dan bahan organik sedimen. Sedangkan variabel pendukung adalah parameter fisika dan kimia yang meliputi $\mathrm{pH}$, salinitas, temperatur dan kecepatan arus. Untuk undur-undur laut yang didapatkan dilakukan perhitungan yang meliputi kelimpahan relatif, kelimpahan per luas area sampling, indeks keanekaragaman, keseragaman dan dominan.

Teknik yang digunakan dalam pengambilan data adalah Purposive random sampling. Teknik ini merupakan pemilihan pengambilan data secara acak dari populasinya yang didasarkan pada pertimbangan yang dibuat oleh peneliti. Teknik pengambilan sampel dilakukan pada tiga stasiun pengamatan yaitu Pantai Sawangan, TPI Pantai Bopong dan Pantai Bopong. Jarak Pantai Sawangan ke TPI Pantai Bopong sejauh $5.72 \mathrm{~km}$ dan jarak TPI Pantai Bopong menuju Pantai Bopong sejauh 2.96 km. Setiap stasiun memiliki empat titik penempatan kuadran transek dengan lebar pada setiap titik yaitu $10 \mathrm{~m} \times 10 \mathrm{~m}^{2}$, dua titik untuk perbandingan jumlah saat pasang dan dua titik untuk perbandingan jumlah saat surut. Jarak antar titik satu dengan yang lainnya yaitu sejauh $10 \mathrm{~m}$ [Gambar 1]. Pengambilan sampel menggunakan teknik aduk di daerah swash zone, yaitu dengan menggali atau mengaduk pasir pada kedalaman tertentu hingga undur-undur laut ditemukan (Darusman et al. 2015).

\section{Kemiringan Pantai}




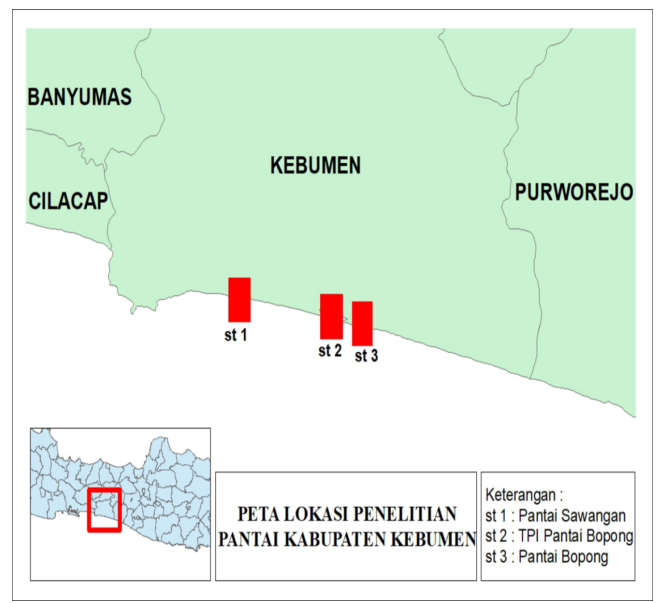

Gambar 1 Peta lokasi penelitian

Tabel 1 Posisi koordinat pengambilan sampel

\begin{tabular}{ccc}
\hline \multirow{2}{*}{ Lokasi penelitian (Stasiun) } & \multicolumn{2}{c}{ Posisi Koordinat } \\
\cline { 2 - 3 } & Lintang Selatan & Bujur Timur \\
\hline Pantai Sawangan (1) & $07^{0} 45^{\prime} 43.90^{\prime \prime}$ & $109^{0} 30^{\prime} 1.03$ ” \\
TPI Pantai Bopong (2) & $07^{0} 46^{\prime} 11.67^{\prime \prime}$ & $109^{0} 33^{\prime} 14.66^{\prime}$, \\
Pantai Bopong (3) & $07^{0} 46^{\prime} 29.95^{\prime}$ & $109^{0} 34^{\prime} 50.53^{\prime}$ \\
\hline
\end{tabular}

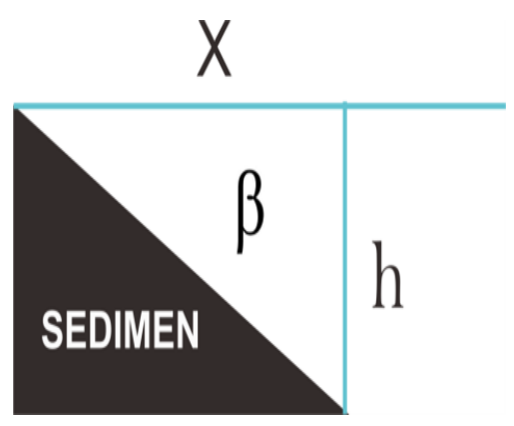

Gambar 2 Sketsa Kemiringan Pantai

Perhitungan kemiringan pantai sesuai dengan sketsa (Gambar 2) menggunakan rumus:

$\tan \beta=\frac{h}{x} \times 100 \%$

dimana: $\beta$ : Sudut kemiringan pantai $h$ : Tinggi (m) $\mathrm{x}$ : Panjang tali $(\mathrm{m})$

\section{Daerah sapuan (swash zone)}

Pengukuran lebar swash zone (Gambar 3) digunakan untuk menentukan lebar habitat undur-undur laut. Cara pengukuran dengan menentukan titik terjauh air laut naik ke permukaan, yang ke-

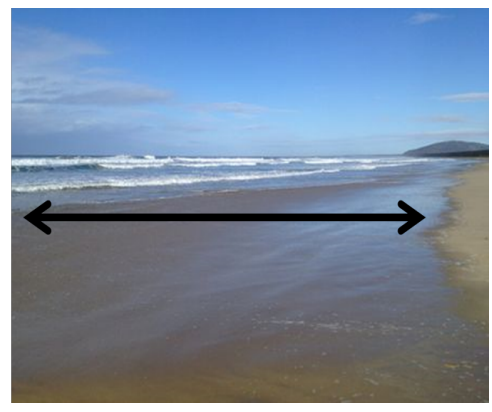

Gambar 3 Area Swash Zone

mudian diukur dengan menggunakan roll meter.

Kelimpahan relatif (KR), indeks keanekaragaman Shanon-Wiener, indeks keseragaman, dan indeks dominasi (D) dapat dihitung dengan menggunakan rumus (Odum, 1971).

$K R=\frac{n i}{N} \times 100 \%$

$H^{\prime}=\sum_{i=1}^{s} p i \ln p i$

dengan

$p i=\frac{n i}{N}$

$E=\frac{H^{\prime}}{H \max }$

$D=\left(\frac{n i}{N}\right)^{2}$

dimana; KR : Kelimpahan relatif; $\mathrm{N}$ : Jumlah total individu; ni : Jumlah individu dari suatu jenis ke $-\mathrm{i}$; H' : Indeks keanekaragaman;E : Indeks keseragaman; $\mathrm{H}$ max : In $\mathrm{S}$ (S jumlah genera); dan D : Indeks Dominasi.

\section{Analisis Ukuran Butiran Sedimen}

Perhitungan persentase berat sedimen dapat diketahui dari masing-masing fraksi sedimen tersebut menggunakan persamaan:

$\%$ berat $=\frac{\text { berat fraksi } i}{\text { berat total sampel }} \times 100 \%$ 
dimana, berat fraksi (i) adalah berat tiap fraksi ukuran butir (g). Penentuan ukuran butir rata-rata dapat diketahui dari masing-masing sampel sedimen tersebut dengan menggunakan persamaan

$d=\sum\left(\frac{\% \text { berat fraksixukuran butir fraksi }}{100}\right)$

dimana; $\mathrm{d}=$ nilai ukur butir rata-rata

\section{Analisis Bahan Organik Sedimen}

Pengukuran bahan organik sedimen dilakukan dengan menggunakan metode LOI (Loss on Ignition) dengan cara sebagai berikut:

$B O S=\frac{\left(w_{t}-c\right)\left(w_{a}-c\right)}{\left(w_{t}-c\right)} \times 100 \%$

dimana; BOS : Bahan Organik Sedimen; Wt : Berat total crucible dan sampel sebelum dikeringkan; $\mathrm{C}$ : Berat crucible kosong; Wa : Berat total crucible dan sampel setelah kering

Analisis data diolah dengan menggunakan Analisis Principal Component Analysis (PCA) bantuan aplikasi SPSS v.20 dan Past4.0. Analisis PCA merupakan analisis multivariate yang mentransformasi variabel asal yang saling berkoreasi menjadi variabel baru yang tidak saling berkorelasi dengan mereduksi sejumlah variabel. PCA analisis multivariate yang mentransformasi variabel asal yang saling berkoreasi satu dengan lainya menjadi satu set variabel yang baru dan lebih kecil serta saling bebas.

\section{HASIL DAN PEMBAHASAN}

Terdapat tiga jenis undur-undur yang diperoleh di tiga stasiun selama penelitian berlangsung, yaitu Emerita emeritus dan Hippa adactyla yang berasal dari famili Hippidae, serta Albunea
Tabel 2 Kelimpahan per luas area sampling di ketiga lokasi sampling pengamatan

\begin{tabular}{llcc}
\hline \multirow{2}{*}{ Lokasi Penelitian } & \multirow{2}{*}{ Jenis Undur-Undur Laut } & \multicolumn{2}{c}{ Kelimpahan ind/100m ${ }^{2}$} \\
\cline { 3 - 4 } Pantai Sawangan & Pasang & Surut \\
\hline \multirow{5}{*}{ TPI Pantai Bopong } & Emerita emeritus & 220 & 378 \\
& Hippa adactyla & 11 & 47 \\
& Albunea symmysta & 3 & - \\
& Emerita emeritus & 214 & 509 \\
& Hippa adactyla & 21 & 11 \\
& Albunea symmysta & 1 & 1 \\
& Emerita emeritus & 239 & 449 \\
& Hippa adactyla & 9 & 14 \\
& Albunea symmysta & 2 & 1 \\
\hline
\end{tabular}

symmysta dari famili Albunea. Jumlah keseluruhan undur-undur laut yang diperoleh selama penelitian yaitu 2130 ekor yang terdiri dari 2009 ekor spesies $E$. emeritus, 113 ekor $H$. adactyla dan 8 ekor A. symmysta. Hasil kelimpahan relatif spesies paling tinggi ditemukan di setiap lokasi adalah E. emeritus baik pada kondisi pasang maupun saat kondisi surut (Tabel 2).

Kelimpahan undur-undur saat surut lebih tinggi dibandingkan saat pasang. Hal ini diduga karena saat surut undur-undur laut lebih mudah untuk menggali sedimen pasir sebagai tempat untuk mencari makanan yang berupa detritus. Hal ini diperkuat oleh Dewi et al. (2019) yang menyatakan bahwa undur-undur laut mencari makan berupa detritus saat air laut surut.

Spesies yang paling tinggi ditemukan di setiap lokasi pengamatan adalah $E$. emeritus baik pada kondisi pasang maupun saat kondisi surut (Tabel 2). Menurut Wardiatno et al. (2014), undurundur laut terutama genus Emerita lebih menyukai pantai dengan tipe dissipative karena secara umum ketersediaan sumber makanan di pantai bertipe dissipative relatif lebih tinggi. Menurut Mashar et al. (2014) bahwa undurundur laut genus Emerita, terutama spe- 
sies E. emeritus banyak tersebar di pantai berpasir wilayah Asia Tenggara.

Spesies $H$. adactyla yang didapatkan dari hasil penelitian memiliki jumlah yang jauh lebih sedikit dibandingkan dengan E. emeritus. Hal ini menunjukan bahwa $E$. emeritus mendominasi pada ketiga pantai. Berdasarkan penelitian Pratiwi (2013) bahwa di Pantai Bocor Kebumen jenis E. emeritus ditemukan $84.08 \%$ lebih banyak daripada spesies lainnya. Perbedaan jumlah tangkapan dari spesies undur-undur laut yang didapat semata-mata karena adanya perbedaan karakteristik habitat dari masingmasing spesies.

A. symmysta merupakan spesies yang paling sedikit ditemukan pada penelitian ini, hanya ditemukan 3 di Pantai Sawangan, 2 di TPI Pantai Bopong, dan 3 di Pantai Bopong, hal ini sesuai dengan penelitian yang dilakukan oleh Sarong dan Wardiatno et al. (2014), famili Albuneid lebih menyukai habitat dengan komposisi pasir berwarna putih susu dan putih keabu-abuan. Menurut Mashar et al. (2014), famili Albuneid umumnya hidup didaerah subtidal, maka apabila disuatu pantai berpasir ditemukan undur-undur laut famili Hippidae, jarang sekali ditemukan famili Albuneid, begitu juga sebaliknya. Genus Albunea masih dapat di temukan pada kedalaman sekitar $50-150 \mathrm{~cm}$ (Mashar et al., 2014).

Hasil perhitungan indeks keanekaragaman $\left(\mathrm{H}^{\prime}\right)$, indeks keseragaman (e) dan dominasi (D) tersaji pada Tabel 3. Nilai indeks keanekaragaman saat pasang sebesar $0.16-0.33$ dan saat surut sebesar $0.10-0.35$. Hasil tersebut memberikan informasi bahwa keanekaragaman undur-undur laut di ketiga pantai tergolong rendah. Menurut Odum (1971), jika nilai keanekaragaman atau $\mathrm{H}^{\prime} \leq 2$ maka keanekaragaman rendah. Rendahnya nilai keanekaragaman ini dikarenakan masing-masing spesies yang ditemukan di ketiga pantai memiliki karakteristik habitat yang berbeda-beda. Umumnya undur-undur laut hidup di pantai terbuka terutama pantai dengan pasir berwarna hitam (pasir besi) pada daerah sapuan / swash zone. Menurut Mashar et al. (2014), undur-undur laut jenis $H$. adactyla hidup pada daerah intertidal dan secara umum banyak dijumpai di perairan Australia.

Hasil nilai indeks keseragaman (e) saat terjadi pasang pada ketiga pantai yaitu $0.15-0.30$ dan saat terjadi surut berkisar $0.09-0.32$ nilai tersebut menunjukan keseragaman yang kecil karena nilai e $<0.4$. Nilai indeks keseragaman dapat dipengaruhi oleh kelimpahan makanan dan kompetisi. Telah diketahui bahwasanya pantai selatan Jawa Tengah memiliki tipe pantai dissipative dimana pantai dengan tipe ini memiliki kelimpahan makanan bagi biota pantai yang melimpah, kecilnya nilai indeks keseragaman ini diduga karena adanya kompetisi memperoleh makanan antar biota di ketiga pantai yang digunakan untuk penelitian. Hal ini serupa dengan peneltian yang dilakukan oleh Dewi et al. (2019) nilai indeks keseragaman undurundur laut saat surut berkisar antara 0.149 -0.343 dan saat pasang berkisar 0.065 - 0.474. Menurut Sidik et al. (2016) semakin kecil nilai indeks keseragaman, maka semakin kecil pula keseragaman populasinya, hal ini menunjukan penyebaran jumlah individu pada setiap jenis tidak sama.

Hasil nilai dominasi (D) yang didapatkan (Tabel 4) menunjukkan bahwa dari ketiga pantai seluruhnya didominasi 
Tabel 3 Hasil analisis indeks keanekaragaman, indeks keseragaman undur-undur laut

\begin{tabular}{ccccccc}
\hline \multirow{2}{*}{ Lokasi penelitian } & \multicolumn{3}{c}{$\mathrm{H}^{\prime}$} & & \multicolumn{2}{c}{$\mathrm{e}$} \\
\cline { 2 - 6 } & Pasang & Kategori & Surut & Kategori & Pasang & Kategori \\
\hline Pantai Sawangan & 0.26 & Rendah & 0.35 & Rendah & 0.23 & Rendah \\
TPI Pantai Bopong & 0.33 & Rendah & 0.1 & Rendah & 0.3 & Rendah \\
Pantai Bopong & 0.16 & Rendah & 0.17 & Rendah & 0.15 & Rendah
\end{tabular}

Tabel 4 Hasil analisis dominasi undur-undur laut

\begin{tabular}{lllll}
\hline Lokasi penelitian & Pasang & Kategori & Surut & Kategori \\
\hline Pantai Sawangan & 0.88 & Terdapat dominasi & 0.79 & Terdapat dominasi \\
TPI Pantai Bopong & 0.82 & Terdapat dominasi & 0.99 & Terdapat dominasi \\
Pantai Bopong & 0.93 & Terdapat dominasi & 0.92 & Terdapat dominasi \\
\hline
\end{tabular}

oleh spesies E. emeritus. Nilai dominasi paling besar oleh spesies E. emeritus yaitu pada TPI Pantai Bopong saat surut, sebesar 0.99 yang tergolong dalam dominasi tinggi $\mathrm{D}>0.6$ dan dominasi terendah oleh spesies $A$. symmysta pada TPI Pantai Bopong sebesar 0.000004 pada saat surut. Dominasi spesies E. emeritus pada ketiga pantai berkisar antara $0.79-0.99$. Apabila indeks dominasi mendekati angka 1 , berarti ada salah satu genera yang mendominasi dan diikuti dengan nilai indeks keseragaman kecil (Sidik et al., 2016). Hal ini sesuai dengan hasil yang didapatkan saat penelitian.

Hasil analisis kemiringan pantai didapatkan bahwa ketiga pantai memiliki tipe yang sama yaitu sangat landai. Pantai Sawangan memiliki kemiringan berkisar $0.92-4.01^{0}$ saat pasang dan 1.03 - 3.92 ${ }^{0}$ saat surut, TPI Pantai Bopong berkisar $1.26-3.29^{0}$ saat pasang dan $1.23-3.94^{0}$ saat surut. Pantai Bopong memiliki kemiringan $1.09-3.46^{0}$ pada saat pasang dan $0.95-2.61^{0}$ pada saat surut.

Berdasarkan hasil tersebut, undur-undur laut di pantai selatan Kabupaten Kebumen memiliki karakteristik habitat pada pantai yang memiliki kemiringan bertipe sangat landai. Pantai di selatan Ka-
Tabel 5 Hasil pengukuran rata-rata lebar swash zone di ketiga lokasi sampling pengamatan

\begin{tabular}{lccc}
\hline \multirow{2}{*}{ Lokasi Penelitian } & \multicolumn{3}{c}{ Lebar Swash Zone (m) } \\
\cline { 2 - 4 } & Pengulangan & Pasang & Surut \\
\hline \multirow{3}{*}{ Pantai Sawangan } & I & 17 & 23.5 \\
& II & 24.5 & 32.5 \\
\multirow{5}{*}{ TPI Pantai Bopong } & III & 16 & 20 \\
& I & 25 & 29 \\
Pantai Bopong & II & 19.5 & 31 \\
& III & 17 & 27 \\
& I & 22 & 28 \\
& II & 14.5 & 31 \\
& III & 15 & 20 \\
\hline
\end{tabular}

bupaten Kebumen rata-rata memiliki tipe pantai yang landai dan berombak besar. Hal ini juga akan sangat berpengaruh terhadap luasnya daerah sapuan (swash zone), sehingga luas daerah hidup undur-undur laut akan semakin lebar.

Sedimen pasir ketiga pantai tersebut memiliki karakteristik yang hampir sama yaitu relatif berwarna abu-abu kehitaman (Tabel 6). Jenis E. emeritus yang paling mendominasi, hal ini dimungkinkan bahwa habitat dari E. emeritus adalah pada pasir berwarna abu-abu kehitaman. Bahan organik pada setiap stasiun memiliki nilai yang rendah saat pasang dan surut berkisar antara 1.68 $1.92 \%$. Nilai bahan organik yang dihasilkan dari ketiga pantai tergolong dalam kriteria yang sangat rendah yaitu $<3.5 \%$ (Tabel 7). Jenis sedimen berpasir memiliki kandungan bahan organik yang rendah (Darusman et al., 2015). Hal ini karena pada sedimen pasir memungkinkan terjadinya proses oksidasi yang baik akibat adanya pore water yang lebih besar, sehingga bahan or- 
ganik akan cepat habis. Undur-undur laut hidup pada pantai berpasir hitam yang memiliki nilai bahan organik rendah pada daerah swash zone dan terdapat sumber makanan berupa detritus. Ukuran butiran sedimen pada ketiga stasiun tergolong pasir sedang $(0.25-0.5 \mathrm{~mm})$.

Salinitas dari ketiga stasiun di Pantai selatan Kabupaten Kebumen yaitu berkisar antara 33 - 40 ppt. Temperatur berkisar antara $27-30{ }^{\circ} \mathrm{C}$. Temperatur merupakan salah satu faktor pembatas ekosistem dan biota laut, perubahan temperatur mempengaruhi proses fisik, kimia dan biologi (Rustam and Prabawa, 2015). Kecepatan arus berkisar antara $0.25-0.66 \mathrm{~m} / \mathrm{s}$. Kecepatan arus akan mempengaruhi kemiringan pantai dan lebar swash zone yang menjadi habitat undur-undur laut. Nilai $\mathrm{pH}$ berkisar antara $5-6.5$ di tiga stasiun penelitian.

Analisis data menggunakan metode PCA (Principal Component Analysis) dengan bantuan software SPSS v.20 dan Past4.0 terhadap beberapa faktor yaitu kelimpahan, bahan organik, swash zone dan butir sedimen. Untuk melihat lebih jelas jumlah hasil ekstraksi dan faktor yang telah terbentuk dapat dilihat dari nilai eigenvalues, variansi dan cummulative. . Didapatkan dua kelompok faktor saat terjadi pasang yaitu faktor satu yang terdiri dari bahan organik, swash zone, dan butir sedimen yang memiliki nilai eigenvalues sebesar 2.321 dan kelompok faktor kedua yaitu kelimpahan dengan nilai eigenvalues sebesar 1.004. Kumulatif faktor yang telah terbentuk yaitu faktor $1=58.033$ dan faktor 2 $=83.14$. Artinya 83.14 kumulatif dapat terbentuk oleh faktor 2. Kelompok faktor yang terbentuk saat surut hanya satu faktor yaitu yang terdiri dari ke- limpahan, bahan organik, swash zone, dan butiran sedimen yang memiliki nilai eigenvalues sebesar 2.148 dan terbentuk satu variansi yaitu faktor $1=$ 53.709 dari $100 \%$ jumlah variansi. Hasil kumulatif memiliki nilai yang sama dengan nilai variansi faktor yaitu 53.709 .

Hasil analisis PCA menunjukan eratnya hubungan kelimpahan dengan butiran sedimen saat pasang. Menurut Wardiatno et al. (2014), keberadaan undurundur laut di Pantai Cilacap ditemukan pada ukuran butir sedimen $0.5 \mathrm{~mm}$, sama halnya dengan hasil penelitian ini, pada ketiga stasiun memiliki ukuran butir sedimen yang sama yaitu pasir sedang $(0.25-0.5 \mathrm{~mm})$ yang merupakan habitat yang sesuai dengan jenis E. emeritus. Saat surut hubungan kelimpahan dengan swash zone yang terbentuk erat kaitannya, hal ini dapat dijelaskan semakin luas area swash zone maka kelimpahan undur-undur akan tinggi, karena semakin luas juga area hewan tersebut untuk mencari detritus.

\section{SIMPULAN}

Jenis undur-undur laut yang ditemukan saat pasang dan surut yaitu $E$. emeritus, $H$. adactyla dan A. symmysta. Kelimpahan per luas area sampling dari ketiga pantai berkisar antara 214 $239 \mathrm{ind} / 100 \mathrm{~m}^{2}$ saat pasang dan 378 509 ind/100 m² saat surut. Karakteristik habitat undur-undur laut di pantai Kabupaten Kebumen memiliki karakter dissipative (tipe pantai dengan gelombang besar, substrat pasir dan memiliki swash zone lebar), dengan kemiringan pantai yang dikaterogikan landai hingga sangat landai, lebar swash zone sebesar $15-24.5 \mathrm{~m}$ saat pasang 
Tabel 6 Hasil analisis fisik sedimen habitat undur-undur laut

\begin{tabular}{|c|c|c|c|c|c|}
\hline \multirow{2}{*}{ Lokasi penelitian } & \multirow{2}{*}{ Warna sedimen } & \multicolumn{4}{|c|}{ Ukuran butir sedimen $(\mathrm{mm})$} \\
\hline & & Pasang & Kategori & Surut & Kategori \\
\hline Pantai Sawangan & & $0.30-0.37$ & & $0.29-0.38$ & \\
\hline TPI Pantai Bopong & Abu-abu kehitaman & $0.26-0.36$ & Sedang & 0.27 & Sedang \\
\hline Pantai Bopong & & $0.28-0.37$ & & $0.26-0.35$ & \\
\hline
\end{tabular}
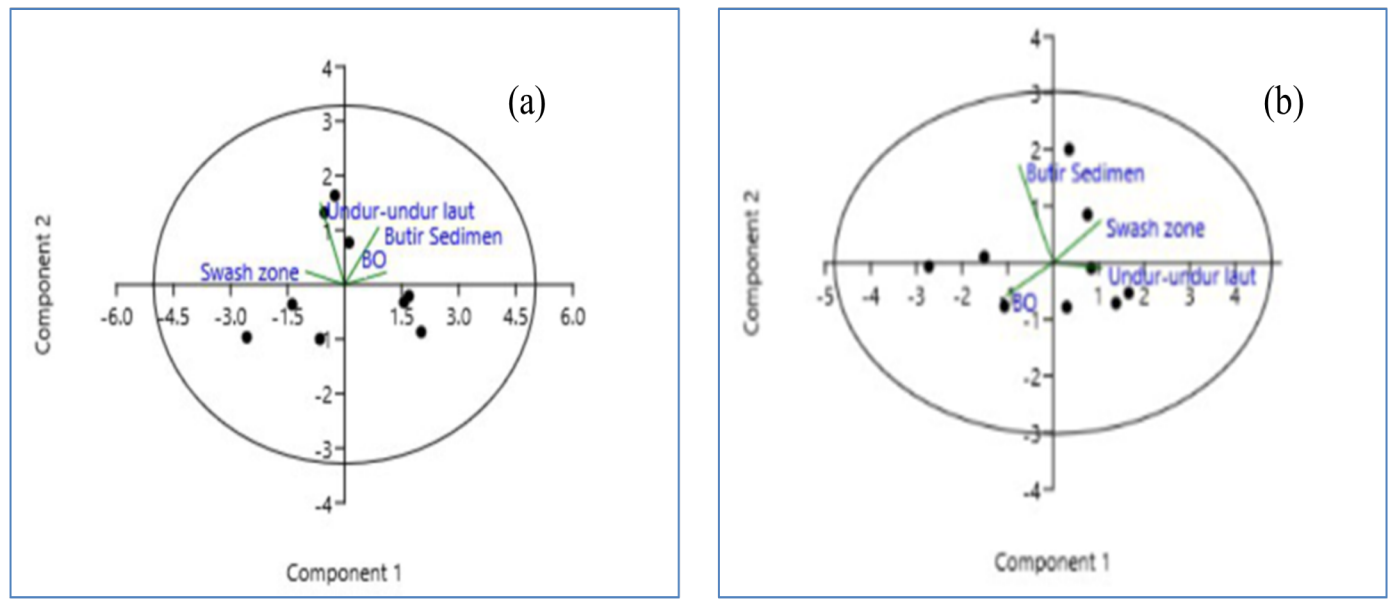

Gambar 4 Hasil Analasis PCA (Principal Component Analysis) saat saat pasang [a] dan saat surut [b]

Tabel 7 Hasil analisis bahan organik sedimen

\begin{tabular}{|c|c|c|c|c|}
\hline \multirow{2}{*}{ Lokasi penelitian } & \multicolumn{4}{|c|}{ Bahan Organik (\%) } \\
\hline & Pasang & Kategori & Surut & Kategori \\
\hline Pantai Sawangan & $1.49-1.92$ & & $1.63-1.92$ & \\
\hline TPI Pantai Bopong & $1.42-1.67$ & Rendah & $1.52-1.88$ & Rendah \\
\hline Pantai Bopong & $1.63-1.90$ & & $1.65-1.78$ & \\
\hline
\end{tabular}

dan saat surut sebesar $20-32.5 \mathrm{~m}$, dengan pasir berwarna hitam keabu-abuan hingga hitam pekat, memiliki nilai bahan organik yang rendah dan didominasi oleh pasir berukuran sedang. Hasil analisis PCA (Principal Component Analysis) menunjukan bahwa variabel bahan organik, lebar swash zone dan ukuran rerata butiran sedimen berada pada satu kelompok faktor yang memiliki keterkaitan dengan kelimpahan undur-undur laut. Kelimpahan undurundur memiliki keterkaitan yang erat dengan variabel butiran sedimen saat pasang dan swash zone saat surut.

Acknowledgements : Ir. Siti Rudiyanti, M.Si dan Dr. Ir. Bambang Sulardiono, M.Si serta Oktavianto Eko Jati, S.Pi., M.Si serta seluruh pihak yang telah memberikan saran dan masukan atas perbaikan artikel ini.

\section{Pustaka}

Darusman, V., Muskananfola, M. R., et al. (2015). Kelimpahan undur-undur laut (hippidae) dan sebaran sedimen di pantai pagak kecamatan ngombol, purworejo, jawa tengah. Journal of Management of Aquatic Resources, 4(1):9-18.

Dewi, W. K., Suryanti, S., and Purnomo, P. W. (2019). Habitat preferences and abundance of mole crab at spring and neap tide in coastal area of purworejo central java, indonesia. International Journal of Applied Environmental Sciences, 14(4):383-394.

Mashar, A., Wardiatno, Y., Boer, M., Butet, N. A., et al. (2014). Diversitas dan kelimpahan kepiting pasir di pantai selatan jawa tengah. Indonesian Journal of Marine Sciences, 19(4).

Odum, E. P. (1971). Fundamentals of Ecology-3rd Edifion. WB Saunders Co., Philadelphia, 574pp.

Pratiwi, M. (2013). Studi pertumbuhan undur-undur laut emerita emeritus (decapoda hippidae) di pantai bocor, kecamatan buluspesantren, kebumen. Bogor: Fakultas Perikanan dan Ilmu Kelautan. Institut Pertanian Bogor.

Rustam, A. and Prabawa, F. Y. (2015). Kualitas perairan di pantai punai dan pantai tambak kabupaten belitung timur. J. Segara, 11(1):75-84.

Sidik, R. Y., Dewiyanti, I., and Octavina, C. (2016). Struktur komunitas makrozoobentos dibeberapa muara sungai kecamatan susoh kabupaten aceh barat daya. $\mathrm{PhD}$ thesis, Syiah Kuala University.

Wardiatno, Y., Nurjana, I. W., and Mashar, A. (2014). Karakteristik habitat undur-undur laut famili hippidae di pantai berpasir, kabupaten cilacap. Jurnal Biologi Tropis, 14(1):1-8. 
Kontribusi: Desi,T: pengambilan data, analisis data dan penulis isi artikel; Suryanti, S: penanggungjawab artikel dan originalitas, isi serta pengambilan keputusan; Widyorini, N: membantu dalam melengkapi artikel 
